\title{
Tobacco use prevalence and correlates among adolescents in a clinician initiated tobacco prevention trial in California, USA
}

Melbourne F Hovell, Donald J Slymen, Kristen J Keating, Jennifer A Jones, Susan Burkham-Kreitner, C Richard Hofstetter, David Noel, Budd Rubin

\begin{abstract}
Objectives - Baseline data for the clinician initiated, tobacco prevention trial, the first non-school based clinician mediated tobacco prevention study, were used to explore the degree to which young people receiving orthodontic treatment use tobacco and the differences in use rates between national, California, and patient samples. Correlates of tobacco use were identified and these correlates were contrasted with findings from the published reports.
\end{abstract}

Design and setting - A 26 item telephone survey assessed demographic information, tobacco use, selected health related behaviours, and variables based on social learning theory. The study was conducted among 11 to 18 year old orthodontic patients from San Diego, Orange, Riverside, San Bernardino, and Los Angeles Counties, California, USA.

Participants - Of the 17925 patients who were eligible, 16915 (>94\%) completed the survey.

Measurements and main results - Multivariate analyses were conducted using a logistic mixed effects model. Although the 30 day prevalence rate of tobacco use $(6 \%$, $n=1010)$ proved lower than California and national samples, the rates for the age, gender, and race ethnicity subgroups showed trends similar to those seen in California and national samples. Ten variables were significantly associated with tobacco use $(p<0.05)$, including 30 day alcohol use $(O R=7 \cdot 88)$, age $(O R=1 \cdot 32)$, and living with a tobacco user $(O R=1 \cdot 72)$. Conclusions - Because $6 \%$ of orthodontic patients use tobacco, interventions are warranted to reach the health "Objectives for the Nation". Patterns of correlates of tobacco use were essentially the same for orthodontic patients, California, and national samples, suggesting that these associations are generalisable.

( $($ Epidemiol Community Health 1996;50:340-346)

Smoking is responsible for more than one of every six deaths in the United States, and continues to be the single most important preventable cause of death in our society. ${ }^{1}$ More than half of all smokers start using tobacco before age 18, and almost $90 \%$ start by age
$21 .^{2}$ About $16 \%$ of adolescents in the United States are smokers. ${ }^{3}$ Given the magnitude of the tobacco epidemic in the youth population, along with the limited success of cessation efforts $^{4-6}$ and school based prevention efforts, innovative prevention interventions in alternative settings are needed. ${ }^{7}$ One possibility for prevention is the use of clinicians to advise young people not to start smoking, analogous to the NCI clinician mediated cessation studies and other studies that have demonstrated that physicians' and dentists' advice to quit can increase quit rates and lengthen the patient's life..$^{8-12}$

It is important to understand the variables that contribute to tobacco use in young people when designing effective tobacco prevention programmes for adolescents. Prior research has indicated six categories of variables that contribute to youth tobacco use: (1) demographics, (2) school activities, (3) family smoking behaviour, (4) peer smoking behaviour, (5) psychological variables, such as low self esteem, and (6) knowledge and attitudes about smoking. The information learned regarding these variables can be used to design tobacco prevention interventions for youth.

Past analyses have found that boys tend to have higher tobacco use prevalence rates than girls, with the gap closing for cigarette smoking in recent years. ${ }^{313}$ The prevalence rates among adolescents tend to be highest for whites, followed by Hispanics, blacks, and Asians. ${ }^{31314}$ Tobacco use rates increase with age, with as much as a sixfold increase from those aged $12-13$ to those aged $16-17 .^{1415}$ Studies have indicated that tobacco use is greatest among those teenagers who are average or below average students (relative to their peers), and the rates decline in those students who report better school performance. ${ }^{14-17}$ Although socioeconomic status (SES) variables are usually related to risk practices, only a few studies conclusively document the influence of variables such as parent education on tobacco use specifically. ${ }^{18-20}$

Family and peer smoking behaviour have been found to be the most influential factors in tobacco use in young people, consistent with social learning theory (SLT) ${ }^{21-23}$ SLT can guide the selection of variables for investigation in order to identify possible determinants of tobacco use. Dimensions such as modelling, self efficacy, and social prompting and reinforcement may be associated with tobacco use, and if associated tend to confirm this 
theoretical model as well as provide a strong basis for designing intervention programmes. A review of the published reports indicates that the single most important factor promoting substance use (including tobacco) is whether significant others, such as parents, older siblings, and friends, engage in substance use. Direct modelling of health damaging activities by parents, teachers, and other models provides a potent influence on adolescents' behaviour choices. ${ }^{24}$ Presumably, repeated positive reactions from friends influence adolescents' tobacco use behaviour. ${ }^{1625}$

Recommendations have been made for clinicians to expand their role to incorporate prevention of smoking initiation among their adolescent patients. ${ }^{26}$ Orthodontists, because they see large numbers of young people repeatedly over two or more years, are especially well suited for testing questions about the effectiveness of clinicians' ability to prevent tobacco use. However, use of orthodontists raises questions about the representativeness of adolescents receiving this treatment and the degree to which results from such a clinician sample could be generalised to other clinicians. It is generally accepted that orthodontic patients represent higher income families and may not use tobacco as much as general populations, which may effect the generalisability of the study. This analysis used baseline data collected as part of the clinician initiated tobacco prevention program, ${ }^{27}$ the first nonschool based clinician mediated tobacco prevention study, (1) to explore the degree to which young people receiving orthodontia use tobacco, (2) to investigate the differences in use rates between national, California, and patient samples, (3) to identify the correlates of tobacco use among orthodontia patients and (4) to contrast these correlates with similar findings from the published reports. Results will provide initial evidence regarding the likelihood that findings from orthodontists may be generalisable to other clinicians working with adolescents.

\section{Methods}

A total of 154 orthodontic practices from San Diego, Orange, Riverside, and parts of Los Angeles and San Bernardino Counties were enrolled in a clinician initiated tobacco prevention trial designed to determine whether clinician counselling can prevent initiation of tobacco use. A random sample of $58 \%$ of each office's eligible 11 to 19 year old patient population was invited to complete an interview concerning health practices. This proportion represents the average number of age eligible patients per office required to attain the necessary statistical power.

Young people were sent passive consent letters explaining the study to them and to their parents, and alerting them to the forthcoming telephone interview. Those surveys that could not be completed by telephone were completed by mail. The young people were informed that the information they provided would be confidential. The survey was completed by 16915 adolescents. All those who completed the survey were entered into a lottery and the winner received a cash award. After baseline measures were obtained, each of the 154 orthodontic practices was randomly assigned to either a control group or an experimental group for the two year duration of the clinical trial.

\section{MEASURES}

The questionnaire consisted of 24 "yes" or "no" questions and two categorical measures (grade and ethnicity), representing: demographics, health attitudes/behaviours, social support for smoking, and intentions to smoke (Appendix A).

Young people were classified as tobacco users if they reported having used cigarettes, pipes, cigars, or smokeless tobacco) during the past day, week, or month. The relationship between 30 day smoking prevalence and 16 selected characteristics (demographics and potential behavioural risk factors) was examined. Three variables (willingness to accept tobacco from friend, offered tobacco in past 30 days, friends avoid people who smoke) were examined in univariate analyses only, because, a priori, one would expect them to be highly correlated with smoking and because these variables may represent proxy measures to tobacco use rather than predictors.

\section{ANALYSES}

Analyses were conducted using $S P S S / P C+$ and EGRET software. Univariate analyses were carried out using a logistic mixed effects model. Each included a particular risk factor and a random effects term to account for the clustering within the orthodontist office. Although one would not expect a high degree of clustering, the use of this model is consistent with the study design where orthodontist office was the unit of randomisation. However, tobacco use, health behaviours, and social support for smoking were measured on the individual adolescents. Results are reported for the risk factors (negative health behaviours) only (not the random effects term) since the clustering is considered a "nuisance" parameter.

A multivariate analysis was carried out in a forward stepwise manner for two reasons. Firstly, we consider this an exploratory analysis where the emphasis is on identifying a subgroup of possible risk factors rather than testing the relationship of each in the presence of well known effects. Secondly, the concern over collinearity favours a forward stepwise approach so that highly correlated independent variables will not be included in the same model at any step.

Due to the complex nature of carrying out a stepwise analysis within a mixed effects model, the stepping process was performed using logistic regression with the random effects term removed. The steps were then reproduced with the random effects term included. We found negligible differences at all steps with and without the random effects term with respect to the regression coefficient estimates and their 
Table 1 Current tobacco use rates compared with California and national samples

\begin{tabular}{|c|c|c|c|}
\hline Variable & $\begin{array}{l}\text { Present study* } \\
(\%)\end{array}$ & $\begin{array}{l}\text { State† } \\
(\%)\end{array}$ & $\begin{array}{l}\text { National } \$ \\
(\%)\end{array}$ \\
\hline $\begin{array}{l}\text { Total } \\
\text { Gender: }\end{array}$ & $6 \cdot 0$ & $9 \cdot 3$ & $15 \cdot 7$ \\
\hline $\begin{array}{l}\text { Male } \\
\text { Female }\end{array}$ & $\begin{array}{l}6 \cdot 2 \\
5 \cdot 8\end{array}$ & $\begin{array}{l}9 \cdot 7 \\
8 \cdot 9\end{array}$ & $\begin{array}{l}16 \cdot 1 \\
15 \cdot 4\end{array}$ \\
\hline Age: & & & \\
\hline $\begin{array}{l}12-13 \\
14-15 \\
16-17 \\
16-18\end{array}$ & $\begin{array}{r}1 \cdot 0 \\
5 \cdot 6 \\
11 \cdot 2 \\
12 \cdot 2\end{array}$ & $\begin{array}{r}2 \cdot 9 \\
7 \cdot 2 \\
19 \cdot 5 \\
\text { NA }\end{array}$ & $\begin{array}{l}3.7 \\
13 \cdot 1 \\
\text { NA } \\
24 \cdot 9\end{array}$ \\
\hline Race/ethnici & & & \\
\hline $\begin{array}{l}\text { White } \\
\text { Black } \\
\text { Hispanic } \\
\text { Asian }\end{array}$ & $\begin{array}{l}6 \cdot 4 \\
2 \cdot 5 \\
5 \cdot 7 \\
3 \cdot 6\end{array}$ & $\begin{array}{r}10 \cdot 1 \\
4 \cdot 9 \\
9 \cdot 5 \\
5 \cdot 1\end{array}$ & $\begin{array}{r}17 \cdot 7 \\
6 \cdot 2 \\
11 \cdot 8 \\
\mathrm{NA}\end{array}$ \\
\hline
\end{tabular}

NA $=$ not available. ${ }^{*} n=16915$; † Burns \& Pierce ${ }^{14} ; \ddagger$ Moss, Allen, Giovino \& Mills, $1992 .{ }^{3}$

standard errors. Consequently, we are confident the stepping process would not change if it had been performed using the mixed effects model.

\section{Results}

RESPONSE RATE

After subject selection, 18541 subjects were contacted initially and 616 of those subjects were determined ineligible based on treatment status, age, or sibling already selected for inclusion. Out of the remaining 17925 subjects, surveys were completed by phone or mail for 16915. Mail surveys were used for subjects or parents requesting them, and for subjects unable to be contacted by phone. The 1010 subjects who did not complete the survey were either refusals or non-respondents. Over $94 \%$ of the eligible youth completed the interview.

\section{INSTRUMENT RELIABILITY AND VALIDITY}

Reliability of the measure was estimated by computing the percentage agreement between baseline responses and responses given 48 hours later on a re-interview for a random subsample $(n=100)$ of youth. Agreement for the primary dependent variable (that is, "tobacco use in the last 30 days") for all subjects was $98 / 100=98.0 \%$, and the agreement for the overall questionnaire (for all items) was $96 \cdot 7 \%$.

A limited construct validity test was conducted using Kendall's Tau-b statistic. Based on theoretical foundations and findings of previous research, four measures were hypothesised to be positively associated with tobacco use; age (Tau- $b=0 \cdot 18$ ), alcohol use in the last 30 days (Tau-b $=0 \cdot 36$ ), living with $a$ tobacco user (Tau-b $=0.09)$, and accepting a friends offer of tobacco (Tau-b $=0.66$ ). Two measures were hypothesised to be negatively associated with tobacco use, having friends who make fun of tobacco users (Tau-b $=-0.09$ ) and having friends who avoid tobacco users (Tau-b $=-0 \cdot 28)$. With so large a sample $(n=$ $16915)$, all association were statistically significant $(\mathrm{p}<0.05)$. Therefore, support for these hypotheses was based on the direction and strength of association. All associations were in the expected direction and most were modest or large coefficients.

Biological measures such as saliva testing were not feasible for over 16000 patients where the majority (that is, $>90 \%$ ) were not tobacco users. However, under rigorous research conditions where confidentiality has been assured and accepted, explicit biological validity checks may be omitted without much risk to reliability or validity. ${ }^{28}$ In light of the overall design, sample size, the relatively high reliability and evidence of construct validity, these results were interpreted as reliable and valid estimates of associations and as satisfactory estimates of rates.

\section{DESCRIPTIVE EPIDEMIOLOGY}

About $54.3 \%$ of the 16915 subjects were female, and most subjects $(65.3 \%)$ reported that a member of their household had graduated from college. The subjects ranged from 11 to 19 years of age, with a mean age of $14.4(\mathrm{SD}=$ $1.8)$ years. Subject ethnicities were as follows: $72.3 \%$ were white, $13.0 \%$ Hispanic, $9.0 \%$ Asian, $2 \cdot 8 \%$ black, and $2 \cdot 9 \%$ were not reported. The 30 day prevalence rate for current tobacco use was $6.0 \%$. The rate for ever having used tobacco was $20.0 \%$. Although it is assumed that these rates reflect primarily cigarette use, they may include a small percentage who limit their use to smokeless tobacco.

The 1010 current tobacco users as defined by use in the past 30 days were $52.5 \%$ female, and $62.0 \%$ of the current users reported that a member of their household had graduated from college. Current users ethnicities were $77 \cdot 1 \%$ white, $12 \cdot 5 \%$ Hispanic, $5 \cdot 4 \%$ Asian, $1.2 \%$ black and $3.8 \%$ did not report their ethnicity. Current tobacco user for the following ages: 11-13 years, 14-16 years, 17-18 years, and 19 years were $5.4 \%, 36.8 \%, 38.9 \%$, and $18.9 \%$, respectively. As expected, there was an increase in current tobacco use as age increased, with the exception of the 19 year old group $(p<0.001)$.

COMPARISONS OF RATES WITH OTHER SAMPLES The national teenage attitudes and practices survey (TAPS) from $1989,{ }^{3}$ and tobacco use in California from $1990-1991,{ }^{14}$ were selected for comparison with the present sample. All three samples used 30 day prevalence rates as defining "current tobacco use". Table 1 shows the rates, for orthodontist patients $(6.0 \%)$, California $(9 \cdot 3 \%)$, and the nation $(15 \cdot 7 \%)$. Although the rates for orthodontist patients were consistently lower they followed patterns similar to those of California and the nation, for age, gender, and race/ethnicity.

\section{RISK BEHAVIOURS}

Several risk behaviours were measured because of their potential relationship to tobacco use. These included alcohol use, seatbelt use, hours of sleep per night, and brushing and flossing habits. Hours slept per night, brushing and flossing are reported in the direction of nonuse, or risk. Table 2 lists rates in relation to gender, age, race/ethnicity, and parent education. For alcohol use, the differences within each subgroup (gender, age, race/ethnicity, and 
Table 2 Frequencies and percentages of risk behaviours in relation to demographic subgroups

\begin{tabular}{|c|c|c|c|c|c|}
\hline Variable & $\begin{array}{l}\text { Sample } \\
\text { size } \\
\text { (n) }\end{array}$ & $\begin{array}{l}\text { Current } \\
\text { alcohol use* } \\
(\%)\end{array}$ & $\begin{array}{l}\text { Non-regular } \\
\text { seatbelt use† } \\
(\%)\end{array}$ & $\begin{array}{l}\text { Less than } 8 h \\
\text { sleep per night } \\
(\%)\end{array}$ & $\begin{array}{l}\text { Brushes teeth less } \\
\text { than } 2 \text { times a day } \\
(\%)\end{array}$ \\
\hline $\begin{array}{l}\text { Total } \\
\text { Gender: }\end{array}$ & 16915 & $13 \cdot 0$ & $7 \cdot 0$ & $22 \cdot 0$ & $8 \cdot 0$ \\
\hline $\begin{array}{l}\text { Male } \\
\text { Female }\end{array}$ & $\begin{array}{l}7728 \\
9187\end{array}$ & $\begin{array}{l}13 \cdot 7 \\
11 \cdot 7\end{array}$ & $\begin{array}{l}8 \cdot 6 \\
5 \cdot 6\end{array}$ & $\begin{array}{l}19 \cdot 0 \\
24 \cdot 1\end{array}$ & $\begin{array}{r}12 \cdot 6 \\
4 \cdot 7\end{array}$ \\
\hline $\begin{array}{l}\text { Age: } \\
11 \\
12-13 \\
14-15 \\
16-17 \\
18-19\end{array}$ & $\begin{array}{r}559 \\
5090 \\
6661 \\
3529 \\
1085\end{array}$ & $\begin{array}{r}2 \cdot 7 \\
4 \cdot 8 \\
10 \cdot 7 \\
21 \cdot 7 \\
36 \cdot 5\end{array}$ & $\begin{array}{l}1 \cdot 6 \\
5 \cdot 3 \\
7 \cdot 6 \\
9 \cdot 0 \\
7 \cdot 2\end{array}$ & $\begin{array}{r}3 \cdot 8 \\
9 \cdot 0 \\
21 \cdot 4 \\
36 \cdot 7 \\
44 \cdot 7\end{array}$ & $\begin{array}{r}12 \cdot 3 \\
9 \cdot 3 \\
8 \cdot 0 \\
7 \cdot 2 \\
7 \cdot 5\end{array}$ \\
\hline $\begin{array}{l}\text { Race/ethnicity } \\
\text { White } \\
\text { Black } \\
\text { Hispanic } \\
\text { Asian }\end{array}$ & $\begin{array}{r}12226 \\
479 \\
2200 \\
1515\end{array}$ & $\begin{array}{r}13 \cdot 0 \\
8 \cdot 0 \\
14 \cdot 3 \\
7 \cdot 1\end{array}$ & $\begin{array}{r}5 \cdot 3 \\
8 \cdot 4 \\
14 \cdot 2 \\
8 \cdot 2\end{array}$ & $\begin{array}{l}19 \cdot 7 \\
23 \cdot 7 \\
24 \cdot 4 \\
33 \cdot 3\end{array}$ & $\begin{array}{l}9 \cdot 0 \\
8 \cdot 8 \\
5 \cdot 7 \\
5 \cdot 8\end{array}$ \\
\hline $\begin{array}{l}\text { Parent college } \\
\text { graduate: } \\
\text { No } \\
\text { Yes }\end{array}$ & $\begin{array}{r}4815 \\
11038\end{array}$ & $\begin{array}{l}13 \cdot 1 \\
12 \cdot 7\end{array}$ & $\begin{array}{l}9 \cdot 7 \\
5 \cdot 7\end{array}$ & $\begin{array}{l}22 \cdot 7 \\
22 \cdot 0\end{array}$ & $\begin{array}{l}7 \cdot 3 \\
8 \cdot 7\end{array}$ \\
\hline
\end{tabular}

* Current alcohol use $=$ alcohol use in previous 30 days; $\nmid$ non-regular seatbelt use $=$ does not usually wear a seatbelt when riding in cars.

Table 3 Univariate odds ratios using logistic mixed effects model to assess relationships between 30 day tobacco use and selected characteristics

\begin{tabular}{|c|c|c|}
\hline Chracteristic & $\begin{array}{l}\text { Prevalence } \\
\text { odds ratio }\end{array}$ & $\begin{array}{l}\text { (95\% CI of } \\
\text { odds ratio) }\end{array}$ \\
\hline $\begin{array}{l}\text { Age (continuous) } \\
\text { Gender (female/male) }\end{array}$ & $\begin{array}{l}1.62 \\
0.93\end{array}$ & $\begin{array}{l}(1.56,1.68) \\
(0.82,1.06)\end{array}$ \\
\hline \multicolumn{3}{|l|}{ Race/ethnicity (reference: white): } \\
\hline Black & $0 \cdot 38$ & $(0.21,0.68)$ \\
\hline Hispanic & 0.91 & $(0.74,1 \cdot 11)$ \\
\hline Asian & 0.55 & $(0.41,0.73)$ \\
\hline Other & $1 \cdot 12$ & $(0.78,1.61)$ \\
\hline Either parent college graduate (yes/no) & 0.81 & $(0.71,0.94)$ \\
\hline 30 day alcohol use (yes/no) & $14 \cdot 3$ & $(12 \cdot 5,16 \cdot 4)$ \\
\hline Live with tobacco user (yes/no) & $2 \cdot 11$ & $(1 \cdot 86,2 \cdot 41)$ \\
\hline Friends think smokers look "cool" (yes/no) & 1.83 & $(1 \cdot 48,2 \cdot 25)$ \\
\hline More popular if tobacco user (yes/no) & 1.52 & $(1 \cdot 05,2 \cdot 21)$ \\
\hline Usually wear a seat belt (yes/no) & $0 \cdot 31$ & $(0 \cdot 26,0.37)$ \\
\hline Usually get $\geq 8 \mathrm{~h}$ sleep (yes $/ \mathrm{no}$ ) & $0 \cdot 31$ & $(0.27,0.35)$ \\
\hline Usually floss teeth $\geq 1 \times$ per day (yes/no) & 0.52 & $(0.44,0.61)$ \\
\hline Usually brush teeth $\geq 2 \times$ per day (yes/no) & 0.75 & $(0.61,0.93)$ \\
\hline \multicolumn{3}{|c|}{ Weight category (reference: neither too much or too little): } \\
\hline Too much & $1 \cdot 72$ & $(1.48,1.99)$ \\
\hline Too little & 1.41 & $(1 \cdot 17,1 \cdot 69)$ \\
\hline Accept tobacco offer from friend (yes/no)* & $158 \cdot 7$ & $(127 \cdot 7,197 \cdot 3)$ \\
\hline Been offered tobacco past 30 days (yes/no)* & $27 \cdot 9$ & $(23 \cdot 8,32 \cdot 6)$ \\
\hline Friends avoid people who smoke (yes/no) ${ }^{*}$ & 0.078 & $(0.065,0.093)$ \\
\hline
\end{tabular}

* Excluded from multivariate analysis.

parent education) were significant $(\mathrm{p}<0.001)$, with the exception of those with $(12 \cdot 7 \%)$ and without $(13.1 \%)$ a college educated parent $(p>0.05)$. For the seatbelt, sleeping, and brushing variables, all differences were significant $(\mathrm{p}<0.05)$ except for one. Hours of sleep per night between subjects with $(22.0 \%)$ and without $(22.7 \%)$ a college educated parent was not significant $(\mathrm{p}>0.05)$.

Table 3 displays univariate associations. With the exception of gender all relationships were statistically significant $(p<0 \cdot 05)$. Smoking increased with age. Based on the age range in this study, every one year increase was associated on average with a $62 \%$ increase in the odds of smoking. The univariate results suggest blacks and Asians smoke less than whites, while Hispanics and "others" are comparable with whites.

Adolescents in households where either parent was a college graduate had a lower odds of smoking than those who lived in households where neither parent graduated from college. Thirty day alcohol use had a highly significant association with smoking $(p<0 \cdot 001)$. Alcohol users were over 14 times as likely to be smokers as non-users. Subjects who lived with a tobacco user were over twice as likely to be smokers as those who did not live with a tobacco user. Having friends who thinks smoking looks "cool" and "more grown up" was associated with smoking. Belief in being "more popular" if a tobacco user, was marginally associated with smoking $(p=0.027)$.

Usually wearing a seatbelt, getting at least eight hours of sleep, flossing at least once per day, and brushing at least twice per day were associated with reduced odds of smoking. Seatbelt users and those getting at least eight hours of sleep had about one third the odds of smoking as those who did not usually practice these behaviours. The questions concerning weight were constructed into a three category variable based on subjects who felt they weighed (1) neither too much nor too little, (2) too much, or (3) too little. The latter two categories were associated with higher rates of smoking than those who felt neither over or under weight. The last three variables listed in table 3 were, as expected, highly associated with smoking. Subjects who would accept an offer of tobacco from a friend, who have been offered tobacco 
Table 4 Final model based on forward stepwise logistic mixed effects model to evaluate 30 day tobacco use and its relationship to selected characteristics $(n=14862)$

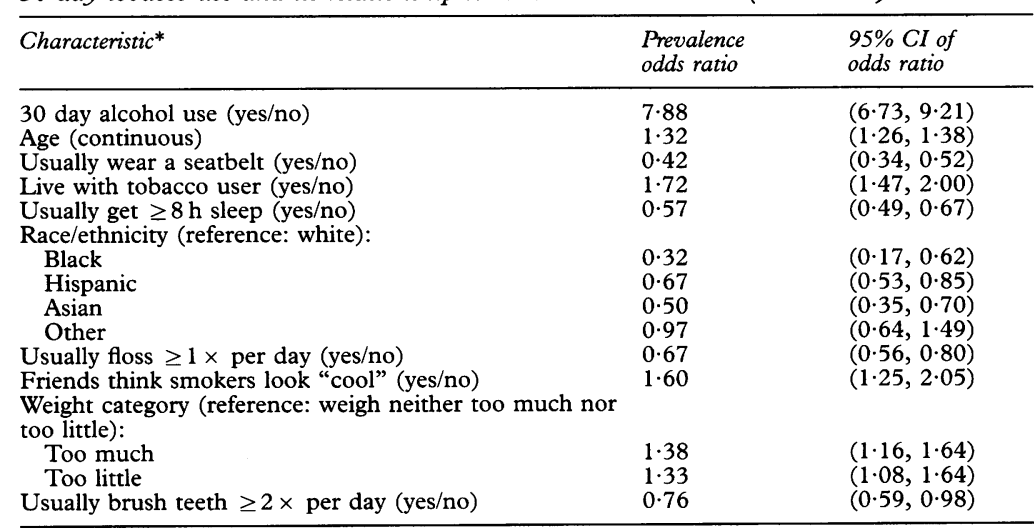

* Three variables did not enter the model: gender, either parent a college graduate, and more popular if a tobacco user.

in the past 20 days, and who have friends who do not avoid people who smoke are all very highly correlated with smoking.

Results from the forward stepwise logistic regression are displayed in table 4 . Due to missing data on one or more of the 13 variables, $2053(12 \cdot 1 \%)$ subjects were not available for this analysis $(n=14862)$. The variables in table 4 are listed by order of entry with the odds ratios and $\mathrm{p}$ values taken from the final model. All but three variables entered the model based on an alpha less than 0.05 . Gender, college education status of parents, and popularity if a tobacco user were not significant $(p>0.05)$ after adjusting for the previously entered variables. Thirty day alcohol use was the first variable to enter; its final odds ratio was $7 \cdot 88$. Although down from its univariate odds ratio of $14 \cdot 3$, this remained highly statistically significant $(\mathrm{p}<0.001)$. Other variables associated with smoking in order of entry were: older age, not usually wearing a seatbelt, living with a tobacco user, not usually getting eight or more hours of sleep, race/ethnicity, not usually flossing at least once per day, having friends who think smokers are cool, weighing too much or too little, and not usually brushing at least twice per day. Blacks, Hispanics and Asians all had lower odds of smoking than whites after adjustment.

Although nearly all variables had odds ratios closer to one in the multivariate model compared with their univariate counterparts, the associations remained statistically significant $(p>0.05)$ and the degree of adjustment was not extensive. The only result which raised a question is parents' college education which did not enter the model. Additional analyses indicate that having at least one parent with a college education was highly associated with usually wearing a seatbelt and not living with a tobacco user, the third and fourth characteristics entering the model. It also was associated with several other variables entering later. Thus, parent education influences on tobacco use may be mediated by these other variables.

\section{Discussion}

The national cancer institute's (NCI) goal for the year 2000 calls for the reduction of ado- lescents' tobacco use in the United States to less than $3 \%{ }^{29}$ School educational efforts are not likely to meet this objective alone. ${ }^{30-32}$ The addition of clinician mediated prevention programmes for adolescents might contribute to this goal. The present analysis explored the degree to which adolescent orthodontic patients exceed the 3\% tobacco use rate, and the degree to which this patient sample is different from California and national samples. This study provides an estimate of the degree to which patients receiving orthodontic treatment warrant tobacco control efforts and an initial estimate of the degree to which results obtained from these patients may predict the results to be obtained from other clinicians' patients.

Youth from 154 private practices in southern California participated. Over $94 \%$ of the eligible youth, more than 16000 , completed the interview. This is the largest study of tobacco use and other health practice for adolescents receiving orthodontic treatment in the published reports. Though tobacco use was self reported, which may have artificially reduced reported rates, the confidential nature of the interview should have enhanced the accuracy of these estimates. This is supported by the high test-retest reliability and the concordance between predicted and observed associations for the construct validity test. Thus, we believe this to be the most reliable estimate of tobacco use and related associations for adolescents receiving orthodontia in the published reports.

Not surprisingly these adolescents came from families who were predominantly white and whose parents had graduated from college. From these patterns it can be concluded that orthodontic patients represent relatively higher SES characteristics than the population at large. This increases the risk of generalisability from this sample to others.

Although our study sample consisted of patients aged 11 to 19 years, comparisons with other databases involved patients age 12 to 18 years in order to match the age groups given by the other databases. The tobacco use prevalence rate for orthodontic patients proved to be $6 \%$ or greater, twice the rate to be achieved for the year 2000 goals for the nation, for all age groups older than 13 years of age. In addition, the tobacco use rates appear to increase substantially with age. These results suggest that adolescent orthodontic patients including those under the age of 14 years warrant efforts to prevent tobacco use initiation. This is especially true when considering risks for "relapse" and the $20 \%$ ever used tobacco rate reported by youth receiving orthodontia. The $6 \%$ rate was about two thirds that of California $(9 \cdot 3 \%)$ and less than one half that of the nation $(15 \cdot 7 \%)$. These differences point out that absolute prevalence rates from adolescents receiving orthodontia should not be used to estimate the rates for more general populations. However, this finding does not necessarily rule out generalisations concerning associations derived from orthodontia samples to samples from other clinical settings.

Inspection of the patterns of tobacco use by gender, age, race/ethnicity, and parent edu- 
cation illustrates essentially the same relationship for the orthodontia, California, and national samples. This suggests that relationships found among this clinical patient sample may represent the same type of relationship for other samples.

Analyses of selected health related behaviours (alcohol use, seatbelt use, sleep habits, and brushing habits) demonstrated that from $7 \%$ to $22 \%$ of the youth engaged in other risk practices, including less than ideal teeth brushing rates. Only $8 \%$ of youth reported irregular brushing. This relatively high rate of compliance with dental practices may represent the results of orthodontists attention or it may represent greater reactivity and reporting error for youth attending orthodontia services. Brushing increased with age, suggesting that proper dental habits stabilised by older adolescence. Males tended to report higher rates of risk behaviours, with the exception of adequate sleeping practices. These findings substantiate Hawkins $^{33}$ conclusion that males are more likely to engage in more problem behaviours (for example, alcohol use, non-regular seatbelt use) than females.

As might be expected, alcohol use and sleeping less than eight hours per night increased with age. Alcohol use was also strongly associated with smoking which is consistent with data collected by the National Institute on Drug Abuse $^{34}$ which indicates that smokers often participate in other risk behaviours. Nonregular seatbelt use increased, then dropped off by ages $18-19$. It is interesting to note that the highest rate of non-regular seatbelt use occurred at the age when most teens are learning to drive, or have typically just received their licence (age 16-17). These rates and relationships, consistent with the published reports, suggest that youth receiving orthodontia may be in need of additional attention in order to reduce these risk practices as well as tobacco use.

When the univariate and multivariate associations between tobacco use and demographic, behavioural, and social variables that might influence tobacco use are considered, essentially the same patterns were observed as have been reported in the published reports. Tobacco use is higher for older youth, those with less educated parents, those who use alcohol or engage in other risk practices. Conversely, tobacco use is lower for adolescents who wear seat belts, get eight hours of sleep, floss and brush their teeth, etc.

The multivariate exploratory analyses of tobacco use resulted in a number of highly associated correlates. After adjustment for demographic variables and using a forward stepping procedure, the most powerful correlates of tobacco use were living with a tobacco user, and friends who think smoking is cool which support SLT. From these findings it appears that attention to social influences for tobacco use offer the most powerful opportunities for prevention. While generalisation from cross sectional associations to causal relationships is ordinarily not justified, in light of similar findings from longitudinal analyses in other populations, ${ }^{3536}$ these conclusions seem parsimonious.

Overall, the results of this study suggest that youth receiving orthodontia warrant attention for tobacco control efforts and that relationships true of patients receiving orthodontia may be generalisable to other populations. This suggests that findings regarding orthodontists' ability to prevent tobacco use among adolescents may be generalisable to physicians and other clinical specialist. Orthodontists' ability to prevent tobacco use in their adolescent patients is currently under investigation by this research group.

\section{Appendix A}

VARIABLE CATEGORIES AND CORRESPONDING ITEMS COMPRISING THE CLINICIAN-INITIATED TOBACCO PREVENTION STUDY QUESTIONNAIRE Demographic

Age (calculated from birth date obtained from patient chart)

Gender (determined from patient chart prior to interview)

"What grade are you in (or going into)?"

"Would you describe yourself as white, black, Hispanic, Asian, or other (describe)"

"Have either of your parents or has anyone you live with graduated from college?"

\section{Health attitudes/behaviours}

"Do you usually wear a seatbelt when you ride in cars?"

"Do you think you weigh too much?"

"Do you think you weigh too little?"

"Do you usually floss your teeth at least once a day?"

"Do you usually brush your teeth at least twice a day?"

"Do you usually get 8 or more hours of sleep each night?"

Alcohol (a "yes" response to any of the following 3 questions qualified as current alcohol use)

"In the past 24 hours have you had any beer, wine, or other alcoholic beverage?"

"In the past week have you had any beer, wine, or other alcoholic beverage?"

"In the past 30 days have you had any beer, wine, or other alcoholic beverage?"

"Have you ever had any beer, wine, or other alcoholic beverage?"

Tobacco (a "yes" response to any of the following 3 questions qualified as current tobacco use)

"In the past 24 hours have you smoked a cigarette, pipe, or cigar or used any form of smokeless tobacco such as snuff or chewing tobacco?"

"In the past week have you smoked a cigarette, pipe, or cigar or used any form of smokeless tobacco?"

"In the past 30 days have you smoked a cigarette, pipe, or cigar or used any form of smokeless tobacco?"

"Have you ever smoked a cigarette, pipe, cigar, or used any form of smokeless tobacco?" "In your whole life do you think you have 
smoked more than 100 cigarettes, pipes, cigars or used any form of smokeless tobacco more than 100 times?"

\section{Social support for smoking}

"Does anyone you live with smoke cigarettes, pipes, cigars, or use smokeless tobacco?"

"If a friend offered you a cigarette, pipe, cigar or some smokeless tobacco would you say yes or no?"

"In the past 30 days have you been offered a cigarette, pipe, cigar or any form of smokeless tobacco?"

"Do most of your friends think people who smoke look 'cool' and 'more grown-up?" "Would you be more popular if you smoked or used smokeless tobacco?"

"Do most of your friends make fun of people who smoke or use smokeless tobacco?"

"Do most of your friends avoid people who smoke or use smokeless tobacco?"

\section{Intentions to smoke}

"Do you think you will smoke or use smokeless tobacco in the next 30 days?"

Supported by funds provided by the Cigarette and Tobacco Surtax Fund of the State of California through the TobaccoRelated Disease Research Program of the University of California, Grant \#2RT0106, awarded to Dr Hovell, and by the Center for Behavioural Epidemiology.

A special thank you to Carey Lyttleton who contributed to this manuscript.

1 Centers for Disease Control. Reducing the health consequences of smoking: 25 years of progress $-A$ report of the Surgeon General. DHHS publication no [CDC] 89-8411. Rockville, MD: US Department of Health and Human Services, Public Health Service, 1989.

2 Kreuter MK, Powell KE. Psychosocial predictors of smoking among adolescents. MMWR 1987;36:1S-2S

3 Moss AJ, Allen KF, Giovino GA, Mills SL. Recent trends in adolescent smoking, smoking-uptake correlates, and expectations about the future. Advance Data No 221. Hyattsville, Md: National Center for Health Statistics, 1992

4 Centers for Disease Control. Smoking cessation duing previous year among adults - United States, 1990 and 1991. MMWR 1993; 42(26):504-7.

5 Hatziandreu EJ, Pierce JP, Lefkoloulou M, Fiore MC, Mills SL. Quitting smoking in the United States in 1986. F Nat Cancer Inst 1990;82:1402-6.

6 Pierce JP, Fiore MC, Novotny TE, Hatziandreu EJ, Davis $\mathrm{RM}$. Trends in cigarette smoking in the United States: projections to the year 2000. FAMA 1989;261(1):61-5.

proj TP

Pierce JP, Evans N, Farkas AJ, et al. Tobacco use in California. an evaluation of the tobacco control prog Health Services, 1994

8 Fiore MC, Pierce JP, Remington PL, Fiore BJ. Cigarette sme clinician's role in cessation, prevention, and smoking: The clinician's role in cessation, pre

9 Gublic health. Dis Mon 1990;36(4) 18. Physician initiated ynn TJ, Manley MW, Pechacek TF. Physician inituated smoking cessation program: The national cancer instutute trials. In: Engstrom et al, eds. Advances in cancer control. 1990:11-25.

10 Kottke TE, Battista RN, DeFriese GH, Brekke ML. Attributes of successful smoking cessation interventions in medical practice: A meta-analysis of 39 controlled trials. fAMA 1988;259:2882-9.
11 Russell MAH, Wilson C, Taylor C, Baker CD. Effect of general practitioners' advice against smoking. BMF 1979 ii:31-235.

12 Rose G, Colwell L. Randomised controlled trial of antismoking advice: final (20 year) results. $f$ Epidemiol Com munity Health 1992;46(1): 75-7.

13 Centers for Disease Control. Tobacco use among high school students - United States. MMWR 1991;40(36) 617-19.

14 Burns D, Pierce JP. Tobacco use in California 1990-1991. Sacramento: California Department of Health Services, 1992.

15 Reimers TM, Pomrehn PR, Becker SL, Lauer RM. Risk factors for adolescent cigarette smoking. Am $\mathcal{F}$ Dis Child 1990;144:1265-72.

16 Botvin GJ, Botvin EM. Adolescent tobacco, alcohol, and drug abuse: Prevention strategies, empirical findings, and 90-301.

17 Schulenberg J, Bachman JG, O'Malley PM, Johnston LD. High school educational success and subsequent substance use: a panel analysis following adolescents into young adulthood. F Health Social Behav 1994;35:45-62.

18 Farrell AD, Danish SJ, Howard CW. Relationship between drug use and other problem behaviors in Urban adolescents. F Consult Clin Psychol 1992;60:705-712.

19 Oetting ER, Beauvais F. Adolescent drug use: Findings of national and local surveys. $\mathcal{f}$ Consult Clin Psychol 1990;58 385-94.

20 Stanton WR, Oei TPS, Silva RA. Sociodemographic charanteristics of adolescent smokers. Int $\mathcal{F}$ Addict 29(7):91325.

21 Bandura A. Social learning and personality development. New York: Holt, Rinehart \& Winston, 1963.

22 Landrine H, Richardson JL, Klonoff EA, Flay B. Cultural diversity in the predictors of adolescent cigarette smoking: the relative influence of peers. F Behav Med 1994;17(3): 331-46.

23 Moreno C, Laniado-Laborin R, Sallis JF, Elder JP, De Moo C, Castro FG, Deosaransingh K. Parental influences on smoking in Latino youth. Prev Med 1994;23:48-53.

24 Curtis S. Promoting health through a developmental analysis of adolescent risk behavior. $\mathcal{F}$ Sch Health 1992;62:417-20.

Collins LM, Sussman S, Rauch JM, et al. Psychosocial predictors of young adolescent cigarette smoking: A sixpredictor study. 7 Appl Soc Psychol 1987;17:554-73.

26 Epps RP, Manley MW. The clinician's role in preventin smod Clin North Am 1992;76(2):43949.

27 Hovell M, Shepherd S, Hofstetter CR, Slymen D. Clinician initiated smoking prevention: a controlled trial. Sacramento, Ca: University of California, Tobacco Related Diseas Research Program, 1991.

28 Akers RI, Massey J, Clarke W, Lauer RM. Are self-reports of adolescent deviance valid? Biochemical measures, randomized response, and the bogus pipeline in smoking behavior. Soc Forces 1983;62:234-51.

29 Greenwald P Sondik EJ. Cancer control objectives for the nation: 1985-2000. Publ No 86-2880. NCI Monograph Washington, DC. Department of Health and Human Services, 1986 .

30 Cleary PD Hitchcock JL, Semmer N, Flinchbaugh LJ, Pinney JM. Adolescent smoking: Research and health policy. Milbank $O$. 1988;66:137-171.

11 Bolt JA Thown S Prol children. Annu Rev Public Health 1988;9:161-201.

32 Elder JP, Wildey MB, De Moor C, et al The long-term prevention of tobacco use among junior high school students: Classroom and telephone interventions. Am $\mathcal{F}$ Public Health 1993;83:1239-44.

33 Hawkins WE. Problem behaviors and health-enhancing practices of adolescents: A multivariate analysis. Health Values 1992;16:46-54.

34 National Institute on Drug Abuse National household survey on drug abuse DHHS Publ No (ADM) 91-1788. WashDC: US Department of Health and Human Services, 1985 .

35 Hovell MF, Hofstetter CR, Sallis JF, Rauh M, Barrington E Correlates of change in walking for exercise: An exE. Correlates of change in walking for exercise: An exploratory analysis. Res $Q$ Ex R, Barrington E. Explanation allis J, Hovell M, Horstetter R, Barrington E. Explanation of virogous physical activity during two years using 